\title{
Assessment of air purifier on efficient removal of airborne bacteria, Staphylococcus epidermidis, using single-chamber method
}

\author{
Jung Hoon Lee • Jeong Yup Kim • Bo-Bae Cho • \\ J. R. Anusha • Ju Yong Sim • C. Justin Raj • \\ Kook-Hyun Yu
}

Received: 13 April 2019 / Accepted: 10 October 2019/Published online: 6 November 2019

(C) Springer Nature Switzerland AG 2019

\begin{abstract}
We evaluated the efficiency of an air purifier using the single-chamber method for the effective removal of airborne Staphylococcus epidermidis, a nosocomial infection-causing bacterium. In this experiment, the bacterial strain $S$. epidermidis was injected using a nebulizer into the test chamber, which was similar to a consumer living space $\left(60 \mathrm{~m}^{3}\right)$. The microbial sampling was conducted via the air sampler method, and the reduction in S. epidermidis growth was monitored by performing three consecutive tests. Initially, a blank test was conducted to determine the natural decay rate and calibrate the experimental setup. After injecting the bacterial strain from 1240 to $11180 \mathrm{CFU}$ per unit
\end{abstract}

Jung Hoon Lee and Jeong Yup Kim contributed equally to this work.

\section{J. H. Lee}

Environmental Convergence Technology Center, Korea Testing Laboratory, 87(Guro-dong), Digital-ro 26-gil, Guro-gu,

Seoul 08389, Republic of Korea

J. Y. Kim · J. R. Anusha · J. Y. Sim • C. J. Raj •

K.-H. Yu $(\bowtie)$

Department of Chemistry, Dongguk University, 26, 3Pil-dong, Jung-gu, Seoul 04620, Republic of Korea

e-mail: yukook@dongguk.edu

B.-B. Cho

Materials Department, Biot Korea Inc., 43-26, Cheomdangwagi-ro, 208 beon-gil, Buk-gu, Gwangju, Republic of Korea

J. R. Anusha

Department of Advanced Zoology and Biotechnology, Loyola College, Chennai, Tamil Nadu 600034, India volume $\left(\mathrm{m}^{3}\right)$, the natural decay rate showed a maximum deviation of $3.1 \%$ with a sampling error of $1.1 \% p$ at a confidence level of $95 \%$. In addition, the particle size distribution in the test chamber was found to range from 0.3 to $5.0 \mu \mathrm{m}$, and a subsequent decrease in large-sized particles was observed with the operation of the air purifier, which is the size similar to that of suspended airborne bacteria. This can be used to assess the performance of the air purifier by calibrating the natural reduction value to the reduced operation value. Thus, the single-chamber technique is a promising approach for analyzing the removal efficacy of airborne bacteria from indoor air.

Keywords Airborne bacteria - Bioaerosols · Airpurifier Single-chamber method $\cdot$ Staphylococcus epidermidis

\section{Introduction}

Recently, the infectious diseases caused by airborne bacteria and viruses are of primary global concern for both social and economic reasons. For example, severe acute respiratory syndrome (SARS) caused the deaths of nearly 700 people and affected almost 8000 during the first outbreak in 2002-2003; it eventually spread around 37 countries, causing a cost of $\$ 18$ billion, primarily in Asia (Sørensen et al. 2006). Moreover, between 2009 and 2010, nearly 17,000 healthy adults died globally from influenza A (H1N1), and the seasonal influenza continues to kill many people annually (Tellier 2009; Chiu et al. 2017). Bioaerosols are airborne 
microorganisms that are either infectious or noninfectious in nature and that can easily spread to the environment via air in a short span of time (Ki Youn et al. 2010). With air as the transportation media, pathogenic bacteria, viruses, fungi, and biological fragments can instantly affect human health (Lee et al. 2008). Generally, these pathogenic bioaerosols enter and exit the respiratory system through breathing, coughing, laughing, sneezing, and personal contact (Shrivastava et al. 2013). Tuberculosis, whooping cough, meningitis, anthrax, and pneumonia are some of the most common examples of airborne bacterial diseases (Eickhoff 1996).

Recently, Staphylococcus, Bacillus, Corynebacterium, and Micrococcus have been recognized as the common genera which have contaminated the environments of a university (Di Giulio et al. 2010), hospitals (Okten and Asan 2012; Ki Youn et al. 2010), offices (Bonetta et al. 2010), and other human dwelling spaces (Frankel et al. 2012). Staphylococci are a common semipathogenic bacterial colonizer in the skin and mucous membranes of humans, and it can cause some minor skin diseases and a multitude of other diseases (Chessa et al. 2016; Lenart-Boron et al. 2017). Staphylococcus epidermidis belongs to the Gram-positive and coagulase-negative Staphylococci which are found in the human skin and mucous membrane (Otto 2009; Wieser and Busse 2000; Taylor et al. 2016); this is the major cause of nosocomial infections and is often the major infective agent in compromised patients, such as drug abusers, immuno-compromised patients, premature newborns, and the elderly (Cuong and Michael 2002; Okten and Asan 2012). The presence of infectious bioaerosols in indoor air is a major issue, and they should be controlled or removed to prevent contagious diseases (Aliabadi et al. 2011).

Generally, removal and disinfection are the two major techniques that have been adopted to control bioaerosols in the environment. In the removal method, an air purifier with filters (high-efficiency particulate air filter) is used to trap and eliminate infectious bioaerosols. In the disinfection method, disinfectants such as a light catalyzer, UV lamp, and chlorine are used to kill the airborne microorganisms (Pham and Lee 2015; Zacarías et al. 2012; Berry et al. 2007). The high-efficiency particulate air (HEPA) filtration technique is effectively used to reduce bioaerosols in laboratories and hospitals (Herrera-Cantú et al. 2017). The major mechanism of the high-efficiency air filter involves removing airborne microparticles from the indoor environment (Mittal et al. 2011). In addition, the indoor installation of an air purifier can significantly reduce airborne bacteria, molds, and mycobacteria. Wen et al. (2014) evaluated the filtration efficiency of a HEPA filter in a biosafety level 3 (BSL-3) laboratory using the aerosolized bacteria, Serratia marcescens, and reported the effective performance of the HEPA filter against these aerosolized bacteria. Moreover, Foarde (2010) used the single-pass method in a chamber filter to evaluate the collection efficiency of filters and the removal of non-biological particles.

The standard for air cleaners was developed in September 1984 by the American Home Appliances Association (AHAM) and reported the test method for particle removal performance of air cleaners. Since then, certification began in August 1985, and the American Heating, Refrigeration and Air-Conditioning Engineers (ASHRAE) standard marks the efficiency of the filter as 16 grades (Medical Advisory Secretariat 2005). The filter test and removal of particles range from 0.3 to $10.0 \mu \mathrm{m}$, and the higher-grade numbers show better performance in particle removal. Thus, considering this filtering efficiency, a reasonable test method is required for the removal of suspended bacteria in living spaces.

In order to understand bioaerosols, they should be collected and identified through standardized sampling techniques with high collection rates. Bioaerosol sampling includes different methods such as impaction, impinger, and filtration (Maimaitireyimu et al. 2015). Among these, impaction is a widely used sampling technique with a high collection rate, through which the bioaerosols are directly collected in the culture medium. The Andersen sampler or slit sampler is used to collect the maximum concentrations of microbes or particle samples using the impaction method (Park et al. 2011; Normand et al. 2016).

In this study, we propose a new method to verify the removal efficiency of airborne bacteria. The ASHRAE standard is just a way to verify the filter, and the proposed method is to evaluate the product in a single chamber. The peculiarity of this study is that it has a built-in HEPA filter installed in a single chamber to evaluate an air cleaner and it prevents contaminations from anything other than the airborne bacteria we use in our experiments. So, we evaluated the efficiency of an air purifier on the removal of the injected bacterial strain, $S$. epidermidis, in a single-test chamber. In this method, the air purifier was installed and tested in a manner similar to a customer's usage conditions. The 
microbial samples were collected from the chamber directly to the agar culture medium using the impaction sampling technique, and then the range of colony formation was analyzed. The natural decay rate, operational decay test, and particle distribution rate were analyzed, and the results were discussed in detail. Through these studies, the bacteria removal performance of the air cleaner was evaluated and it helps the consumers to check the performance in advance.

\section{Materials and methods}

Test chamber and air purifier (HEPA filter) device

The experiment was conducted in a single germless chamber with dimensions of $60.8 \mathrm{~m}^{3}(4.5 \mathrm{~m}(\mathrm{~W}) \times 4.5$ $\mathrm{m}(\mathrm{L}) \times 3 \mathrm{~m}(\mathrm{H})$ ). The air purifier (HEPA filter) device capable of removing airborne particles was installed in the ceiling of the test chamber, and an air conditioning system was assembled to control the interior temperature and humidity (Fig. 1a). Moreover, a nebulizer (Devilbiss PulmoNeb, Compressor, Model 3655, USA) was set up to inject strains at a flow rate of $0.5 \mathrm{ml}$ per minute. The mass median aerodynamic diameter (MMAD) is $5 \mu \mathrm{m}$. In addition, the system contains a device to control the moisture and spraying pressure (48.2 PSI), as well as filters to supply clean air. Figure $1 \mathrm{~b}$ shows a schematic diagram of the air inbuilt purifier used in the experiment. The inbuilt air purifier consists of a primary filter, an activated carbon filter (it helps to remove ozone and odor inside the test chamber), and a HEPA filter for more effective air purification. In the typical experiment, the air purifier was installed in three different ways, which were all similar to a customer's usage conditions. In the first one, a stand type was installed directly on the floor (Fig. 2a), while in the second one, a desktop type was installed at a height of $1.2 \mathrm{~m}$ from the floor (Fig. 2b) and a distance of $0.1 \mathrm{~m}$ from the wall. Finally, in the third one, wall-mounted or ceiling-embedded types were installed at $1.8 \mathrm{~m}$ from the floor of the experimental chamber (Fig. 2c).

Test organism and air sampler

In consideration of the examiner's safety, a nonpathogenic strand, Staphylococcus epidermidis (ATCC 12228), was selected as the representative strain. This selection was made because $S$. epidermidis is one of the signature microorganisms which is found at high rates indoors, and particularly in hospital air and catheters (Kelley and Gilbert 2013). Here, a nutrient solution is needed to incubate $\mathrm{S}$. epidermidis and a nebulizer is utilized to spray into the chamber. The nominal flow of the microbial sampler (Merck, MAS-100 NT, USA) is $100 \mathrm{~L} / \mathrm{min}$. The head diameter is $10 \mathrm{~cm}$, with a sampling volume of $100-1000 \mathrm{~L} / \mathrm{min}$. The sampling volume can be effectively controlled based on the required number of airborne microbes per unit volume.

\section{Buffer solutions and culture media}

The phosphate buffer solution ( $\mathrm{pH}$ 7.2) was prepared by dissolving $34 \mathrm{~g}$ of potassium dihydrogen phosphate in $500 \mathrm{ml}$ of distilled water. Then, $175 \mathrm{ml}$ of sodium hydroxide solution was added so as to adjust the $\mathrm{pH}$ to $\sim 7.1-7.3$, and the solution was then made up to $1000 \mathrm{ml}$ using distilled water. Next, the solution was stored in a refrigerator after undergoing a high-pressure steam sterilization. Prior to the experiment, the solution was diluted at 1:800 and sterilized at $121^{\circ} \mathrm{C}$ for $15-20 \mathrm{~min}$. The buffered peptone water ( $\mathrm{pH}$ 7.0) was synthesized by mixing potassium dihydrogen phosphate $3.56 \mathrm{~g}$, disodium hydrogen phosphate $18.23 \mathrm{~g}$, sodium chloride $4.30 \mathrm{~g}$, and peptone $1.0 \mathrm{~g}$ in $1000 \mathrm{ml}$ of distilled water under heating. Then, the resultant buffered peptone water was sterilized in an autoclave at $121{ }^{\circ} \mathrm{C}$ for 15 $20 \mathrm{~min}$ and the $\mathrm{pH}$ was adjusted to neutral.

The nutrient broth was prepared by dissolving $5.0 \mathrm{~g}$ peptone and $3.0 \mathrm{~g}$ meat extracts in $1000 \mathrm{ml}$ of distilled water, the $\mathrm{pH}$ was adjusted to 7.0-7.4, and then the mixture was sterilized at $12{ }^{\circ} \mathrm{C}$ for $15 \mathrm{~min}$. The nutrient agar was obtained by dissolving $15 \mathrm{~g}$ of purified agar in $1000 \mathrm{ml}$ nutrient broth. After adjusting the $\mathrm{pH}$ to $6.8 \pm$ 0.2 , the mixture was sterilized at $121{ }^{\circ} \mathrm{C}$ for $15 \mathrm{~min}$.

Distribution of airborne particles

The distribution characteristics of the airborne particles inside the chamber were subsequently investigated using a particle counter (Met One, Model 3313). In this analysis, the external air from the outdoor environment was directly introduced into a chamber without passing through a HEPA filter. Then, the chamber was sealed, and the movement characteristics of the airborne particles were measured over time from outside of the chamber via the tubing technique. 
Fig. 1 a Schematic flow chart of the test chamber $60.8 \mathrm{~m}^{3}(4.5 \mathrm{~m}$ $(\mathrm{W}) \times 4.5 \mathrm{~m}(\mathrm{~L}) \times 3 \mathrm{~m}(\mathrm{H}))$. The single chamber is connected with an air flow device, air filter (HEPA), temperature and humidity regulator, flow control device, and temperature and humidity monitoring device. b Typical types of filters used in air purifier device

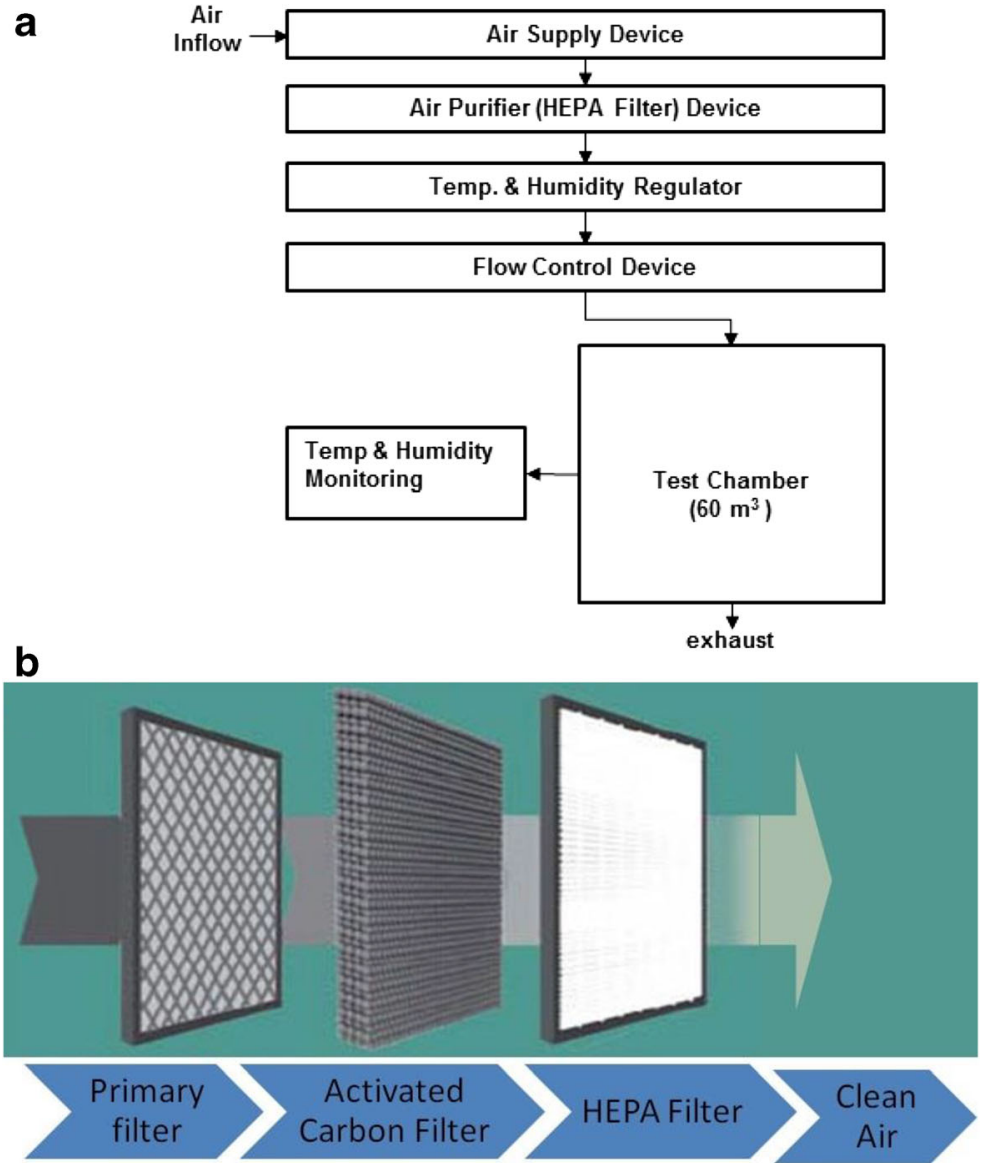

Natural decay test (blank tests)

The natural decay test was conducted before operating the air purifier. The following procedure was performed for the blank test: initially, air purifier (HEPA filter) device (Fig. 1b) in the chamber ceiling was operated for $1 \mathrm{~h}$ so as to remove the airborne bacteria and ozone $(\mathrm{O}(3))$ inside the test chamber, where the temperature and humidity were regulated within $23 \pm 1{ }^{\circ} \mathrm{C}$ and RH $50 \pm 5 \%$ respectively. At this time, the UV lamps were turned on to sterilize the microbes which survived the purification of the HEPA filter. In this case, it is preferable to use activated carbon (AC) filters because a small amount of ozone may be generated. AC filters are used widely in air cleaning to remove ozone (Metts and Batterman 2006). Following this sterilization and removal of ozone, the HEPA filter device and UV lamp were turned off and the auxiliary fan inside the chamber was turned on. Subsequently, the test strand was injected at a rate of $1 \times 10^{5}$ $\mathrm{CFU} / \mathrm{ml}(2 \mathrm{ml})$ using a nebulizer setup. Then, the auxiliary fan was turned off, and the chamber was left to stand for $1 \mathrm{~h}$ without any external disturbance. A microbial culture medium (petri dish) was attached on the air sampler inside the chamber and sampled for $1 \mathrm{~min}$ at a flow speed of $100 \mathrm{~L} / \mathrm{min}$, which was used as an initial value. Similarly, the chamber was left to stand for another $1 \mathrm{~h}$ and sampled for $5 \mathrm{~min}$ at a flow speed of $100 \mathrm{~L} / \mathrm{min}$, which was used as a final value. The initial and final values measured by this procedure were used as the blank test. After measuring the final value, the chamber was sterilized to remove the microbes by powering the UV lamp and operating the stirring plate.

Air purifier test (operational decay test)

In the air purifier evaluation test, the operation of the air purifier (on and off) was completely controlled from 
Fig. 2 a Stand type unit setting. b Desktop type installed at a height of $1.2 \mathrm{~m}$ from the floor and a distance of $0.1 \mathrm{~m}$ from the wall. $\mathbf{c}$ Wall-mounted or ceilingembedded types installed at $1.8 \mathrm{~m}$ from the floor
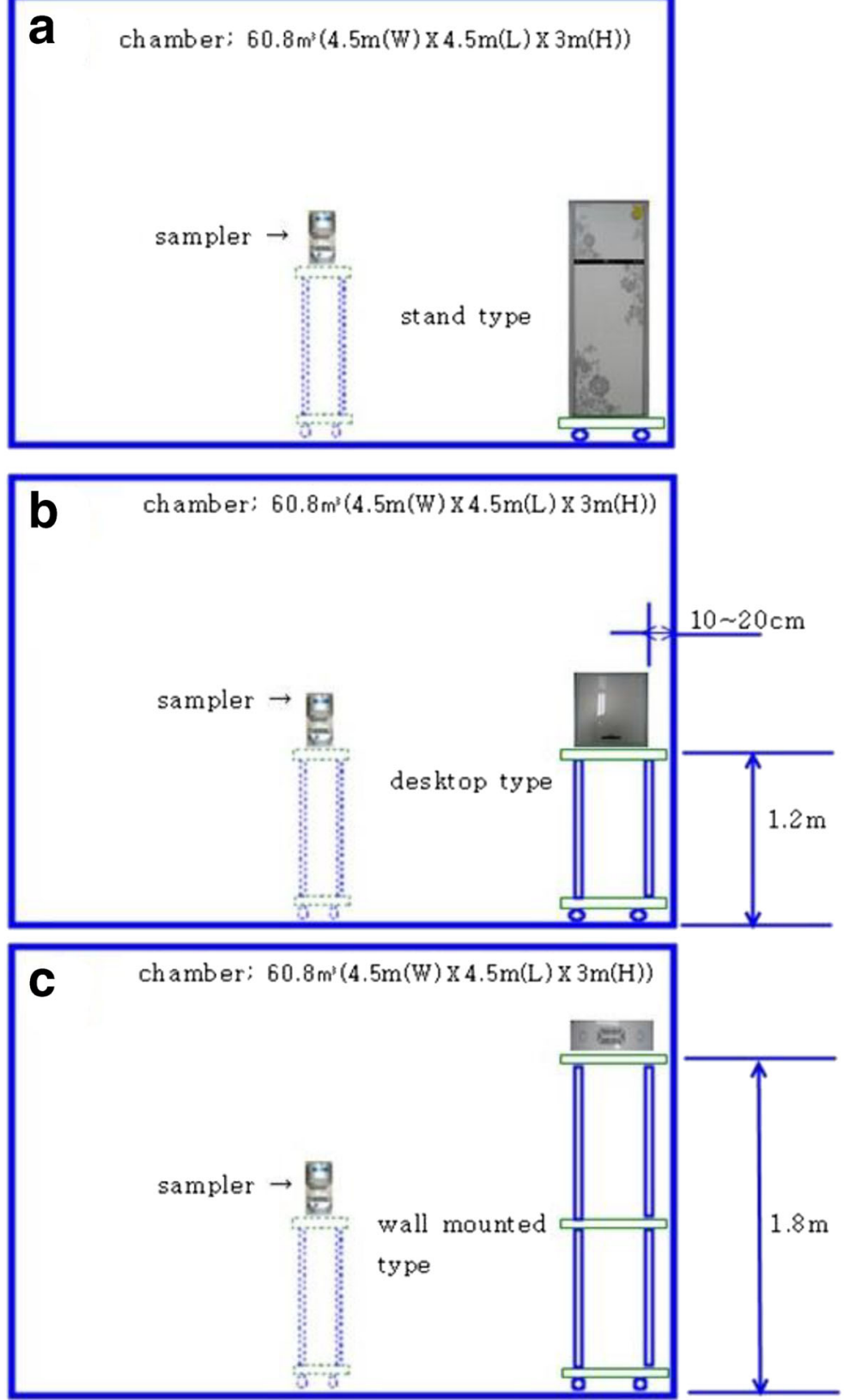

outside of the chamber. Similar to the natural decay test, the test chamber was calibrated to be free from airborne bacteria, and the initial value was measured after injecting the microbial strain. Then, the air purifier was operated for $1 \mathrm{~h}$ and the final value was measured. As the number of airborne microbes relatively decreases due to the high removal performance of air purifier, the sampling volume of the air sampler was increased to $500 \mathrm{~L}$ in order to acquire a more accurate final value.
Sampling of bacteria

Initially, the air sampler lid and cover were sterilized using an autoclave and 70\% alcohol, and the moisture content was completely removed. An impact measurement method was used, in which the bioaerosols can directly contact the medium. The sample collection position was set at the center of the chamber at a height of $1.2 \mathrm{~m}$ from the floor. 
Fig. 3 Distribution percentages of different size particles with respect to time (1 to $6 \mathrm{~h}$ )

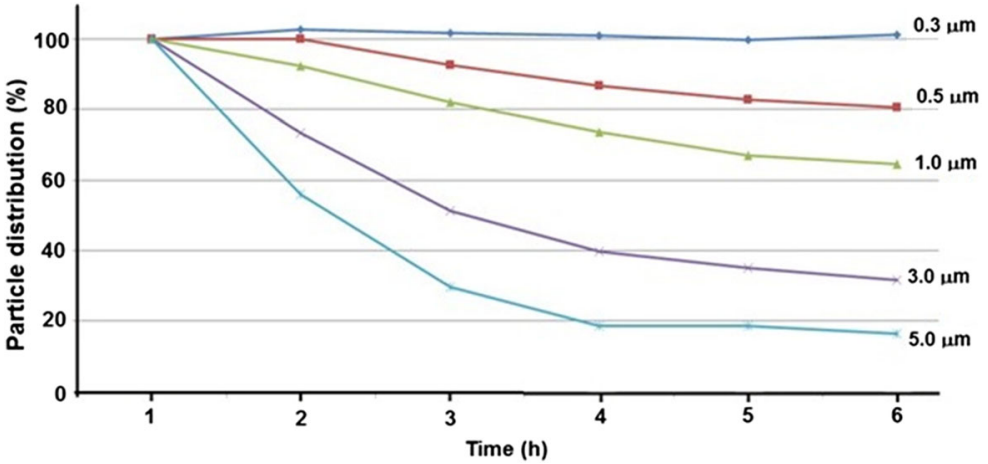

Colony count

Each colony grown in the petri dish was counted, and the number of colonies was corrected by a Feller table. In order to ensure the reliability of measurements and identical trends, the results were carefully reviewed. For accuracy management (QA/ QC), the error range of the natural decay rate was recorded. In this unique study, cultivation was done for $24 \mathrm{~h}$, and the minimum allowed colony was set to $8 \mathrm{CFU}$ per petri dish while the maximum allowed range was fixed below $400 \mathrm{CFU}$ per petri dish.

\section{Calculation}

The natural decay rate was calculated using Eq. (1).

$B_{i}=\left(1-\frac{C_{t}}{C_{i}}\right) \times 100$

\section{then carefully verified for the allowed range of number} of colonies $(\leq 400 \mathrm{CFU} /$ petri dish $)$ as well as contamination of the medium by other sources. The Feller table was applied to the value and corrected with the sample volume in order to obtain CFU value per unit volume $\left(\mathrm{m}^{3}\right)$. where $B_{i}$ is the natural decay rate, $C_{i}$ is the measured value $1 \mathrm{~h}$ after injecting bacteria, and $C_{t}$ is the measured value $2 \mathrm{~h}$ after injecting bacteria.

Table 1 Distributions of different size particles over time from 1 to $6 \mathrm{~h}$

\begin{tabular}{|c|c|c|c|c|c|c|}
\hline \multirow[t]{2}{*}{ Particle size $(\mu \mathrm{m})$} & \multicolumn{6}{|l|}{ Time (h) } \\
\hline & $1: 00$ & $2: 00$ & $3: 00$ & $4: 00$ & 5:00 & $6: 00$ \\
\hline 0.3 & $1,247,053$ & $1,279,256$ & $1,269,741$ & $1,259,171$ & $1,243,333$ & $1,261,025$ \\
\hline 0.5 & 196,298 & 196,215 & 181,629 & 170,027 & 162,282 & 158,351 \\
\hline 1.0 & 17,981 & 16,597 & 14,734 & 13,271 & 12,047 & 11,602 \\
\hline 3.0 & 548 & 402 & 281 & 218 & 192 & 173 \\
\hline 5.0 & 91 & 51 & 27 & 17 & 17 & 15 \\
\hline
\end{tabular}


Table 2 Colony count per unit volume $\left(\mathrm{m}^{3}\right)$ within one hour and the natural decay rate $(\%)$

\begin{tabular}{llll}
\hline S. No. & $0 \min \left(\mathrm{CFU} / \mathrm{m}^{3}\right)$ & $60 \mathrm{~min}\left(\mathrm{CFU} / \mathrm{m}^{3}\right)$ & Natural decay $(\%)$ \\
\hline 1 & 1240 & 260 & 79.03 \\
2 & 2090 & 440 & 78.95 \\
3 & 2460 & 490 & 80.08 \\
4 & 2460 & 522 & 78.78 \\
5 & 2810 & 510 & 81.85 \\
6 & 5610 & 1068 & 80.96 \\
7 & 11,180 & 2370 & 78.80 \\
\hline
\end{tabular}

The initial value's corrected value is calculated using Eq. (2)

$S_{c}=\left(1-\frac{B_{i}}{100}\right) \times P_{t}$

Fig. 4 Survivability of S. epidermidis colony after $1 \mathrm{~h}$ (a) and $2 \mathrm{~h}$ (b) of nebulization

where $S_{c}$ is the initial value's corrected value $\left(\mathrm{CFU} / \mathrm{m}^{3}\right)$, $B_{i}$ is the natural decay rate, and $P_{t}$ is the initial value $\left(\mathrm{CFU} / \mathrm{m}^{3}\right)$.

The airborne bacteria removal rate was defined as

$N_{i}=\left(1-\frac{C_{n}}{S_{c}}\right) \times 100$

where $N_{i}$ is the airborne bacteria removal rate, $S_{c}$ is the initial value's corrected value, and $C_{n}$ is the bacteria measured $n$ hours after injecting bacteria under the operation of an air purifier.

\section{Results and discussion}

Generally, the filters in an air purifier can trap airborne particles by means of size exclusion, in which the air is forced through the filter and the particles are physically

a

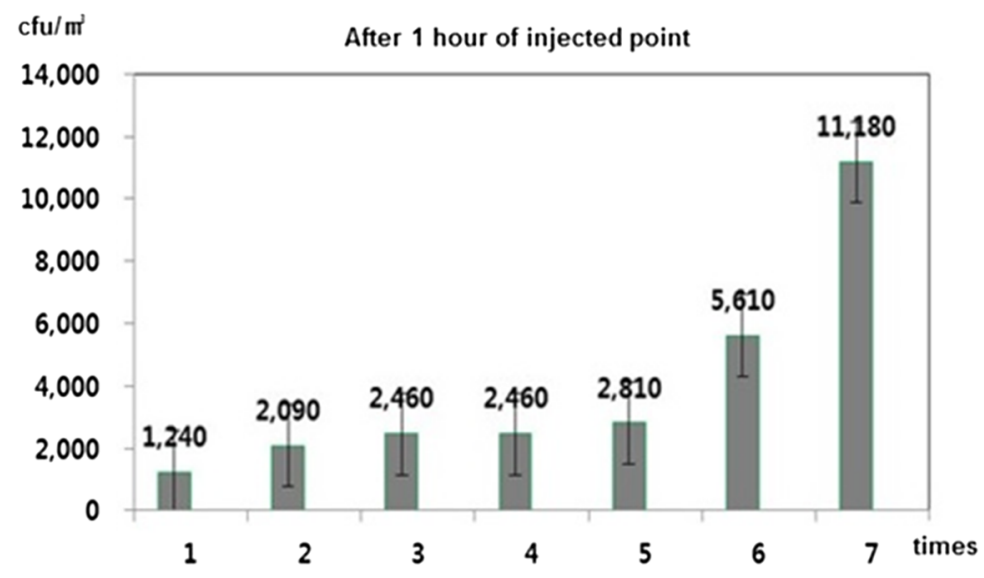

b

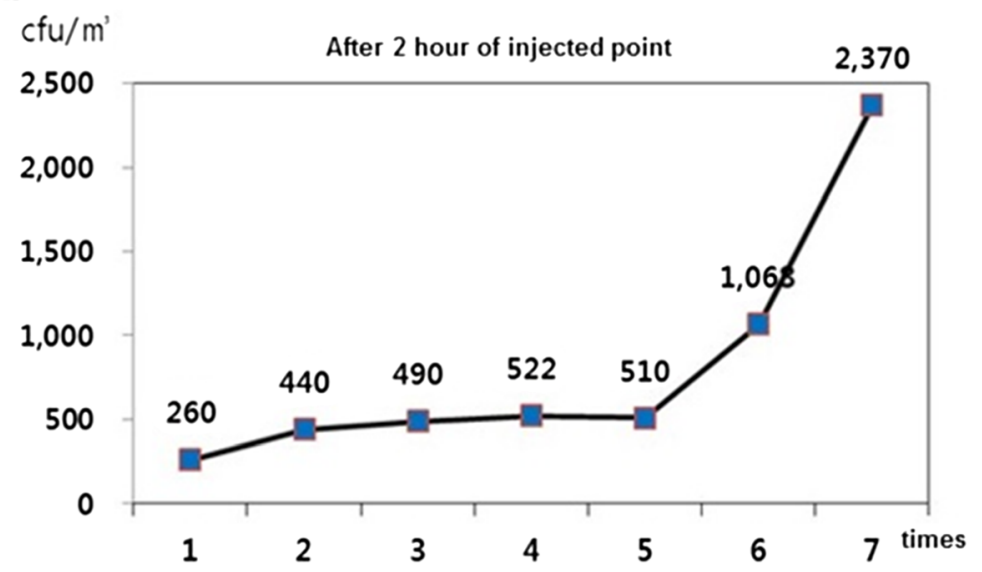


Fig. 5 Colony of S. epidermidis after $24 \mathrm{~h}$ of incubation at $37^{\circ} \mathrm{C}$. a Before operation ( $t=60 \mathrm{~min})$. b After operation $(t=120 \mathrm{~min})$. c Negative control. d Positive control

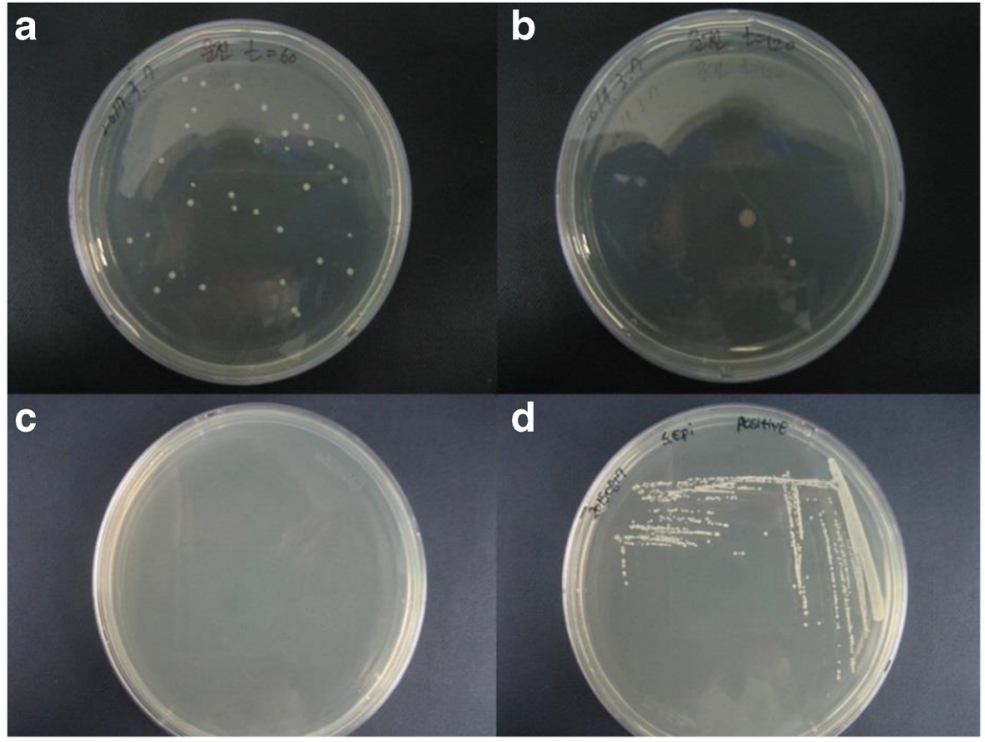

captured. In this present investigation, the size distribution of the particles inside the airtight chamber (analyzed using a particle counter) was found to be in the range of 0.3 to $5.0 \mu \mathrm{m}$ (Fig. 3). The results indicated that the distribution of larger-sized particles decreased over time, due to the performance of the air purifier (Table 1). Here, particles near the size of a microbe (1 $\mu \mathrm{m})$ were also observed to decrease by $\sim 10 \%$ after $1 \mathrm{~h}$ of the experiment. Moreover, the particle size distribution of the bacterial strain also showed a similar decreasing pattern. However, the rates of decrease were higher for the test bacteria than for airborne particles; this may be attributed to the adhesion of microbes with liquid droplets. Therefore, the reduction rate is larger than that of the normal particles, even when the size of the microbes equals $1 \mu \mathrm{m}$. This is because the weights of the microbes increase when combined with liquid droplets, and the particle size has been estimated to be $\leq 5 \mu \mathrm{m}$. Consistent with our data, the microbial size has been shown to range between 1 and $\leq 7.5 \mu \mathrm{m}$ and increase with increasing temperature (Tham and Zuraimi 2005). By contrast, a previous investigation on the size distribution of airborne heterotrophic bacteria has revealed aerodynamic diameters between 1.1 and $2.1 \mu \mathrm{m}$ in one fraction respirable particulate matter and another at the coarse fraction with a diameter above $7 \mu \mathrm{m}$ (Raisi et al. 2012). In addition, the distribution of bacteria has been controlled and influenced by the nebulizer used for the generation of bioaerosols. According to Kujundzic et al. (2006), the aerodynamic size distribution of bacteria generated with the nebulizer can vary due to the generation of particles with both larger and smaller aerodynamic diameters $(0.3-0.6 \mu \mathrm{m})$. But, due to various complexities like coalescence in determining aerosol particle lifetime in the atmosphere, there are very few experimental studies that have been performed to research interparticle interactions (Bzdek and Reid 2017). Moreover, the behavior of the particles mainly depends upon the physicochemical properties like agglomeration state, shape, crystal structure, chemical composition, surface area, surface chemistry, surface charge, and porosity (Oberdörster et al. 2005).

The natural decay test was conducted seven times with bacterial concentrations varying from 1240 to $11,180 \mathrm{CFU} / \mathrm{m}^{3}$ (Table 2). The results indicated that the maximum deviation was $3.1 \%$ with the allowed sample error of $\pm 1.1 \% p$ at a $95 \%$ confidence level. It was observed that the bacteria decrease at a constant rate at constant intervals upon the injection of bacterial strain into the airtight chamber of constant space (Fig. 4a, b). Based on these observations, the results of the operational decay test showed the performance of the air purifier itself by correcting the natural decay rate. The efficiency of the air purifier on the removal of S. epidermidis was found to be similar to that reported by Wen et al. (2014), where $S$. marcescens was effectively filtered by a HEPA filter under the laboratory test unit. Before injecting the microbial samples into the chamber, the internal air in the chamber was cleaned and sterilized. The proliferation of bioaerosols was 
controlled when the air purifier (HEPA filter) device and UV filter were switched on before the natural decay test. The natural decay rate was observed to be in the range from 78.78 to $81.85 \%$ for $60 \mathrm{~min}$. Here, UV is used to sterilize the air, and the particle flow through the HEPA filter comes into contact with the surfaces of the fibers by means of van der Waals forces and removed from the air stream (Taylor et al. 2016). In addition, the test unit (air purifier) was fixed in three different setups, specifically in stand, ceiling, and wall mount types, and they all showed similar removal efficiencies, which would help the product accommodate the lifestyle of the consumer.

The S. epidermidis samples were collected and cultured in nutrient agar plates, and they all resulted in similar-shaped colonies in white color. The raised and cohesive colonies were approximately 1 to $2 \mathrm{~mm}$ in size after incubation at $37^{\circ} \mathrm{C}$ for $24 \mathrm{~h}$ (Fig. 5a, b), and Fig. 5c and $\mathrm{d}$ show the negative and positive controls, respectively. Prior to the air purifier operation, the nebulized bacteria were found to be high and similar to the positive control. Once the airborne microbes were captured by the filter, the rate of suspended bacteria becomes very low or even zero. Thus, the HEPA filters built into air purifiers are made of intertwined fibers, where the smallest particles or microbes become trapped in three ways: interception, impaction, or diffusion. The smallest airborne microbes were most likely trapped in the fibers by means of diffusion. Once the microbes enter into the filter, they will colloid with the gas molecules and embed into the fibers of the filter (Herrera-Cantú et al. 2017). Here, the microbes suffer from lack of nutrients, and the high humidity in this environment leads to low proliferation. In addition, while selecting the test organism, the few criteria were observed, because the test device was a household air purifier; the most important challenge was that the organisms needed to be representative of the bacteria typically found in human dwelling spaces.

\section{Conclusions}

To summarize, the single-chamber technique was adopted to evaluate the efficiency of an air purifier on the removal of airborne bacteria. Programmed and periodic cleaning and sterilization activities of the chamber were performed as a pre-measure for the contaminations. The result suggests that the rate of decrease in microbes in a chamber with injected microbes after some fixed time was constant. The natural decrease rate had a correlation within the range of 1240-11,180 CFU of microbe density per $1 \mathrm{~m}^{3}$. By calibrating the operation value to the natural decay rate, the bacterial removal capability of the air purifier can be verified and the error of the resulting value can be minimized. Thus, this evaluation method for the air purifier device performance is considered to be promising for improving air filtration technology.

\section{References}

Aliabadi, A. A., Rogak, S. N., Bartlett, K. H., \& Green, S. I. (2011). Preventing airborne disease transmission: review of methods for ventilation design in health care facilities. Advances in Preventive Medicine, 2011, 124064. https://doi. org/10.4061/2011/124064.

Berry, D., Mainelis, G., \& Fennell, D. (2007). Effect of an ionic air cleaner on indoor/outdoor particle ratios in a residential environment. Aerosol Science and Technology, 41(3), 315-328. https://doi.org/10.1080/02786820701199702.

Bonetta, S., Bonetta, S., Mosso, S., Sampo, S., \& Carraro, E. (2010). Assessment of microbiological indoor air quality in an Italian office building equipped with an HVAC system. Environmental Monitering Assessment, 161(1-4), 473-483. https://doi.org/10.1007/s10661-009-0761-8.

Bzdek, B. R., \& Reid, J. P. (2017). Perspective: aerosol microphysics: from molecules to the chemical physics of aerosols. J. Chem. Phys, 147, 220901. https://doi.org/10.1063 /1.5002641.

Chessa, D., Ganau, G., Spiga, L., Bulla, A., Mazzarello, V., Campus, G. V., \& Rubino, S. (2016). Staphylococcus aureus and Staphylococcus epidermidis virulence strains as causative agents of persistent infections in breast implants. PLoS One, 11(1), e0146668. https://doi.org/10.1371/journal. pone. 0146668 .

Chiu, S., Black, C. L., Yue, X., Greby, S. M., Laney, A. S., Campbell, A. P., \& de Perio, M. A. (2017). Working with influenza-like illness: presenteeism among US health care personnel during the 2014-2015 influenza season. American journal of infection control, 45(11), 1254-1258. https://doi.org/10.1016/j.ajic.2017.04.008.

Cuong, V., \& Michael, O. (2002). Staphylococcus epidermidis infections. Microbes and infection, 4, 481-489.

Di Giulio, M., Grande, R., Di Campli, E., Di Bartolomeo, S., \& Cellini, L. (2010). Indoor air quality in university environments. Environmental Monitering Assessment, 170(1-4), 509-517. https://doi.org/10.1007/s10661-009-1252-7.

Eickhoff, T. C. (1996). Airborne disease: including chemical and biological warfare. American Journal of Epidemiology, 144(8), S39-S46.

Foarde, K. K. (2010). Development of a method for measuring single-pass bioaerosol removal efficiencies of a room air cleaner. Aerosol Science and Technology, 30(2), 223-234. https://doi.org/10.1080/027868299304804. 
Frankel, M., Beko, G., Timm, M., Gustavsen, S., Hansen, E. W., \& Madsen, A. M. (2012). Seasonal variations of indoor microbial exposures and their relation to temperature, relative humidity, and air exchange rate. Applied and environmental microbiology, 78(23), 8289-8297. https://doi.org/10.1128 /AEM.02069-12.

Herrera-Cantú, I., García-Aguilar, K., Pedraza-Gress, E., Vázquez-López, E., García-Mar, J. J., Flores-González, L. A., et al. (2017). Quantic analysis of the adherence of a gramnegative bacteria in a HEPA filter. International Journal of Advanced Engineering, Management and Science, 3(12), 1122-1125. https://doi.org/10.24001/ijaems.3.12.5.

Kelley, S. T., \& Gilbert, J. A. (2013). Studying the microbiology of the indoor environment. Genome biology, 14(2), 202. https://doi.org/10.1186/gb-2013-14-2-202.

Ki Youn, K., Yoon Shin, K., \& Daekeun, K. (2010). Distribution characteristics of airborne bacteria nad fungi in the general hospital of Korea. Industrial Health, 48, 236-243.

Kujundzic, E., Hernandez, M., \& Miller, S. L. (2006). Particle size distributions and concentrations of airborne endotoxin using novel collection methods in homes during the winter and summer seasons. Indoor Air, 16(3), 216-226. https://doi. org/10.1111/j.1600-0668.2005.00419.x.

Lee, B. U., Sun, H. Y., Ji, J.-H., \& Bae, G.-N. (2008). Inactivation of S. epidermidis, B. subtilis, and E. coli bacteria bioaerosols deposited on a filter utilizing airborne silver nanoparticles. Journal of Microbiology and Biotechnology, 18(1), 176-182.

Lenart-Boron, A., Wolny-Koladka, K., Juraszek, K., \& Kasprowicz, A. (2017). Phenotypic and molecular assessment of antimicrobial resistance profile of airborne Staphylococcus spp. isolated from flats in Krakow. Aerobiologia (Bologna), 33(3), 435-444. https://doi. org/10.1007/s10453-017-9481-7.

Maimaitireyimu, W., Lu, X., Patrick, K. H. L., \& Zhi, N. (2015). Development and laboratory evaluation of a compact swirling aerosol sampler (SAS) for collection of atmospheric bioaerosols. Atmospheric Pollution Research, 6(4), 556-561.

Medical Advisory Secretariat. (2005). Air cleaning technologies: an evidence-based analysis. Ontario Health Technology Assessment Series, 5(17), 1-52.

Metts, T. A., \& Batterman, S. A. (2006). Effect of VOC loading on the ozone removal efficiency of activated carbon filters. Chemosphere., 62(1), 34-44.

Mittal, H., Parks, S. R., Pottage, T., Walker, J. T., \& Bennett, A. M. (2011). Survival of microorganisms on HEPA filters. Applied Biosafety, 16(3), 163-166.

Normand, A. C., Ranque, S., Cassagne, C., Gaudart, J., Sallah, K., Charpin, D. A., et al. (2016). Comparison of air impaction and electrostatic dust collector sampling methods to assess airborne fungal contamination in public buildings. Annals of Work Exposures and Health, 60(2), 161-175. https://doi. org/10.1093/annhyg/mev075.

Oberdörster, G., Maynard, A., Donaldson, K., Castranova, V., Fitzpatrick, J., et al. (2005). Principles for characterizing the potential human health effects from exposure to nanomaterials: elements of a screening strategy. Particle and Fibre Toxicology, 2, 8. https://doi.org/10.1186/17438977-2-8.

Okten, S., \& Asan, A. (2012). Airborne fungi and bacteria in indoor and outdoor environment of the Pediatric Unit of
Edirne Government Hospital. Environmental Monitering and Assessment, 184(3), 1739-1751. https://doi. org/10.1007/s10661-011-2075-x.

Otto, M. (2009). Staphylococcus epidermidis-the 'accidental' pathogen. Nature Reviews Microbiology, 7(8), 555-567. https://doi.org/10.1038/nrmicro2182.

Park, C. W., Yoon, K. Y., Do Kim, Y., Park, J. H., \& Hwang, J. (2011). Effects of condensational growth on culturability of airborne bacteria: implications for sampling and control of bioaerosols. Journal of Aerosol Science, 42, 213-223.

Pham, T.-D., \& Lee, B.-K. (2015). Disinfection of Staphylococcus aureus in indoor aerosols using $\mathrm{Cu}-\mathrm{TiO}_{2}$ deposited on glass fiber under visible light irradiation. Journal of Photochemistry and Photobiology A: Chemistry, 307-308, 16-22. https://doi.org/10.1016/j.jphotochem.2015.04.002.

Raisi, L., Aleksandropoulou, V., Lazaridis, M., \& Katsivela, E. (2012). Size distribution of viable, cultivable, airborne microbes and their relationship to particulate matter concentrations and meteorological conditions in a Mediterranean site. Aerobiologia, 29(2), 233-248. https://doi.org/10.1007 /s10453-012-9276-9.

Shrivastava, S. R., Shrivastava, P. S., \& Ramasamy, J. (2013). Airborne infection control in healthcare settings. Infection Ecology and Epidemiology, 3(1), 21411. https://doi. org/10.3402/iee.v3i0.21411.

Sørensen, M. D., Sørensen, B., Gonzalez-Dosal, R., Melchjorsen, C. J., Weibel, J., Wang, J., Jun, C. W., Huanming, Y., \& Kristensen, P. (2006). Severe acute respiratory syndrome (SARS). Annals of the New York Academy of Sciences, 1067, 500-505.

Taylor, M., McCollister, B., \& Park, D. (2016). Highly bactericidal polyurethane effective against both normal and drug-resistant bacteria: potential use as an air filter coating. Applied Biochemistry and Biotechnology, 178(5), 1053-1067. https://doi.org/10.1007/s12010-015-1928-0.

Tellier, R. (2009). Aerosol transmission of influenza A virus: a review of new studies. Journal of the Royal Society Interface, 6(Suppl 6), S783-S790. https://doi.org/10.1098 /rsif.2009.0302.focus.

Tham, K. W., \& Zuraimi, M. S. (2005). Size relationship between airborne viable bacteria and particles in a controlled indoor environment study. Indoor Air, 15(9), 48-57.

Wen, Z., Yang, W., Li, N., Wang, J., Hu, L., Li, J., et al. (2014). Assessment of the risk of infectious aerosols leaking to the environment from BSL-3 laboratory HEPA air filtration systems using model bacterial aerosols. Particuology, 13, 8287. https://doi.org/10.1016/j.partic.2012.11.009.

Wieser, M., \& Busse, H.-J. (2000). Rapid identification of Staphylococcus epidermidis. International Journal of Systematic and Evolutionary Microbiology, 50, 1087-1093.

Zacarías, S. M., Satuf, M. L., Vaccari, M. C., \& Alfano, O. M. (2012). Efficiency evaluation of different $\mathrm{TiO}_{2}$ coatings on the photocatalytic inactivation of airborne bacterial spores. Industrial and Engineering Chemistry Research, 51(42), 13599-13608. https://doi.org/10.1021/ie3009956.

Publisher's note Springer Nature remains neutral with regard to jurisdictional claims in published maps and institutional affiliations. 